\title{
IMPACT OF SOCIAL MEDIA ON ACADEMIC PERFORMANCE OF GRADUATE STUDENTS IN KATHMANDU
}

\author{
Janga Bahadur Hamal*
}

\begin{abstract}
This study aims to identify the relationship of social media useon academic performance of students. The study is based on 176 sample responses generated from masters' level second semester management students of different universities in Kathmandu. The study used structured questionnaires which constituted multiple choice and Likert scale items for collection of crosssectional data. The study has used descriptive analysis, frequency responses, and Chi-square test in order to identify significant differences in frequency of responses over different Likert scales and association between the variables. The study showed that engagement in social media has a negative relationship on academic performance of students. However, most students feel that its use should not be stopped. The study thus recommends that students need to be informed about pros and cons of social media, and the universities should engage students in teaching learning activities through social media.
\end{abstract}

Keywords: academic performance, social media, student, study hour, test score.

\section{Introduction}

The technological and digital advancement of the world has helped the communication sector take a major leap, as the different social networking sites have greatly facilitated in connecting people (Kolan\&Dzandza, 2018). Its rapid development cannot just be felt in day-to-day communication of individuals but also in its high degree of penetration in wide array of sectors from education to entertainment to conducting business. The platforms created by the internet, also known as social media including Facebook, Twitter, Instagram, LinkedIn, YouTube, and many others, have become a powerful tool in the $21^{\text {st }}$ century as they are used for multitude of activities where individuals create, share and deliberate on different available contents (Mahmud \& Bukhari, 2019).Factors like convenience, flexibility, functionality, and free or marginal cost for use, has increased the adaptation of social media by a phenomenal level (Brown, 2010). Today, social media is considered to be an imperative aspect of individuals' lives (Boyd \& Ellison, 2007). The platforms have indeed made it easier for people to make new connections, and exchange information (Coyle \& Vaughn, 2008). Attributable to the same, social media has contributed immensely to the society by facilitating discourse on numerous important agendas that include, but is not limited to, new trends, environment, politics, cultural backwardness, and many others (Asur\& Huberman, 2010).

\footnotetext{
* Assistant Professor of Saraswati Multiple Campus (Management Faculty), Tribhuvan University, Nepal.
} 
Nowadays, majority of individuals, especially youngsters frequently use social media for purposes like keeping in contact with friends and family, and learning. Thus, interaction in social media has surpassed the different forms of communication that existed traditionally (Baruah, 2012). However, it has been identified that the use of social media has both advantages as well as disadvantages. One of the most phenomenal achievement of social media has been regarding the distribution of knowledge and information amongst a vast group of people which has indeed increased the communication skills and learning skills of students and learners(Licardi et al., 2007).The use of social media has become an integral part for both teachers and students in exchange of knowledge and information. To validate the same, numerous studies have been conducted that portray the benefits of social media on education. Yunus et al. (2012) identified that participation on social networks like Facebook and Twitter helped students to improve their vocabulary as well as writing skills. Likewise, Asad, Mamun and Clement (2012) revealed that social networking sites helped students to exchange assignments, and resources and conduct discussions on academic subjects. While at that, studies have also found social media to have negative or absolutely no effect on education or student performance. Negussie and Ketema (2014) concluded in their study that there is no significant relationship between time spent on social media and students' grade point average (GPA). Ahmed and Qazi (2011) also discovered similar results. Mehmood and Tawir (2013) clarified the variation from their finding thatsocial media networks and the internet can have both negative and positive effect on educational performance of students.

The aforementioned studies distinctly illustrate the controversy regarding the effect of social media on education. While some studies reveal phenomenal contribution of social media towards improvement of academic performance of students, others show that it results in drop in student grades and academic performance as a result of minimal time allocation for studies. With the growing trend of use of social media in education, it is imperative to identify the effect of use of social media or internet on educational performance of students. Its significance lies on understanding the impact on learning skills to help generate policies by both schools and higher education institutes that could facilitate in enhancing the learning ability and pattern of students. Additionally, it is vital for making evidence-based decision not only by educational institutions, but also by policy makers and guardians regarding the use of such social networking sites for the purpose of knowledge and information dissemination.

Devi, Gouthami, and Lakshmi(2019), the knowledge regarding use of social media and its impact is an imperative phenomenon that has insinuations for teaching as well as learning process of both teachers as well as students. It is thus important to identify the gap, if any, in adaptation of social media in terms of enhancing learning experience and leverage it to improve efficiency in educational system. The research on such subjects can thus help to an extent to advance patterns of sharing and exchanging of information, discussing and commenting on ideas, and creating new knowledge. Simply put, it can enhance the learning experience as a whole. This paper thus aims to identify the impact of social media with academic performance of students of graduate level under management faculty in Kathmandu. 


\section{Literature Review}

Peter (2015) revealed that majority of students are addicted to social media and also suggested that there should however be a balance between the use of social media and academic activities to help mitigate the risk of downfall of academic performance. On the other hand, with the help of cross-sectional survey and factor analysis Al-Menayes (2015) concluded that excessive use of social media negatively impacted the academic performance of undergraduate students. Acheaw and Larson (2015) showed that use of social media platforms had a negative and significant relationship with academic performance of the students. The study recommended that students should be encouraged to use the available internet as an alternative source of knowledge and discouraged to overspent time chatting with friends.Mensah and Nizam (2016) revealed that factors like time appropriateness, people-friend connection, nature of usage and health addiction had significant impact on academic performance of students, while time duration and security/privacy had no effect on academic performance. The study suggested that abnormal use of social media by students, it is important for universities and colleges to educate the students on positively using the platforms to enhance the academic performance.

Literature, however, also revealed positive impact of social media on student learning and academic performance. A qualitative study conducted in Beijing Normal University, China in students revealed that social media platforms are highly preferred by students of higher institutions, and they further support the idea that social media contributed significantly to the development of students' academic life (Boateng \&Amankwaa, 2016). The proper usage of social media held significant promise to positively impact academic performance of students. The study went on to acknowledgeas long as students are serious learners, social media re-engages them in the learning process and enhances their academic performance (Onyeka, Sajoh\&Bulus, 2013). Teachers and students should alike avail social media platforms like Facebook, Whatsapp, Twitter and Youtube as interactive forum for teaching and learning activities as they positively contributed to the academic performance of students (Olowo et al., 2020).

The students using the social media platforms for academic purposes instead of non-academic purposes, were found significantly greater and positive impact of the use of social media in their academic performance compared to their counterparts. The study further suggested that if used by educators and teachers as a tool to ease and improve learning environment, then social media holds the promise to enhance students' learning (Sivakumar, 2020). A study of undergraduate level government college students in Kashmir found that these platforms greatly help students to share knowledge and information which students had been using as a tool to enhance their learning (both reading and writing) methods with significant benefit, implying a direct relationship between the two (Palla\& Sheikh 2020). In this way, the study highlighted the importance of incorporating social media platforms in the pedagogical activities of students.

\section{Methodology}

The study has employed the cross-sectional and descriptive research design. For the same, the target population of the study is the number of students studying in second semester of master's level under management stream in Kathmandu valley. The primary data was collected by distributing structured questionnaire to 180 studentsduring October - November 2020, out of 
which 176 (98\%) responses were recorded. Among the respondents, 29 percent of the respondents were studying at TU affiliated colleges 34percent at TU constituent colleges, and 39 percent were affiliated to other universities. The selection of respondents from various campuses, however, were not significantly different $\left(\chi^{2}=0.2621\right)$. The structured questionnaire included multiple choice questions and Likert scale items. The sample students were masters' level second semester management students from 6 different colleges in Kathmandu. For the purpose of descriptive analysis - frequency, percentage, mean and graphical tools have been employed. Likewise, in order to identify significant differences in frequency of responses over different Likert scales and association between the variables, the study has used Chi-square test. The identified findings have been presented in the form of bar graphs, heat plots, density plots and tables.

\section{Results}

\section{Descriptive statistics}

A total of 176master's level second semester management students participated in the survey. Out of the total respondents, majority (57 percent) were male, whereas a significant number (43 percent) were female. More than 50 percent of the respondents were from outside Kathmandu valley. The survey constituted of respondents who belonged to TU constituent colleges (39 percent), TU affiliated colleges ( 29 percent) and other colleges (32 percent). Majority of respondents (36 percent) have used social media for three to six years. A significant number (34 percent) have used social media for six to nine years and 20 percent have used social media for more than nine years. Only nine percent of the respondents have used social media for less than three years.

\section{Table 1}

Profile of respondents

\begin{tabular}{llcc}
\hline Demography & Characteristics & Frequency & Percent \\
\hline \multirow{2}{*}{ Gender } & Male & 100 & 57 \\
& Female & 76 & 43 \\
Address & Inside Kathmandu Valley & 85 & 48 \\
& Outside Kathmandu Valley & 91 & 52 \\
\multirow{5}{*}{ University } & TU constituent & 68 & 39 \\
& TU affiliated & 52 & 29 \\
& Others & 56 & 32 \\
& Less than 1 year & 2 & 1 \\
Use of Social Media & 1-3 year & 15 & 8 \\
& 3-6 year & 63 & 36 \\
& 6-9 year & 60 & 34 \\
& More than 9 years & 36 & 20 \\
\hline
\end{tabular}




\section{Popular Social Media Platform and their Usage}

The results depicted that the most popular social media platform among students is Facebook, followed by Instagram and Viber.Less than 10 percent students reported to be using other forms social media except Facebook, Instagram and Viber.Facebook is the go-to social media platform for majority of students (39.4 percent). It is followed by Instagram (19.4 percent) and Viber (18.1 percent). It further reveals that platforms like LinkedIn which have globally been known to enhance professional networks of users have not gained ground among post-graduate level students in Nepal.

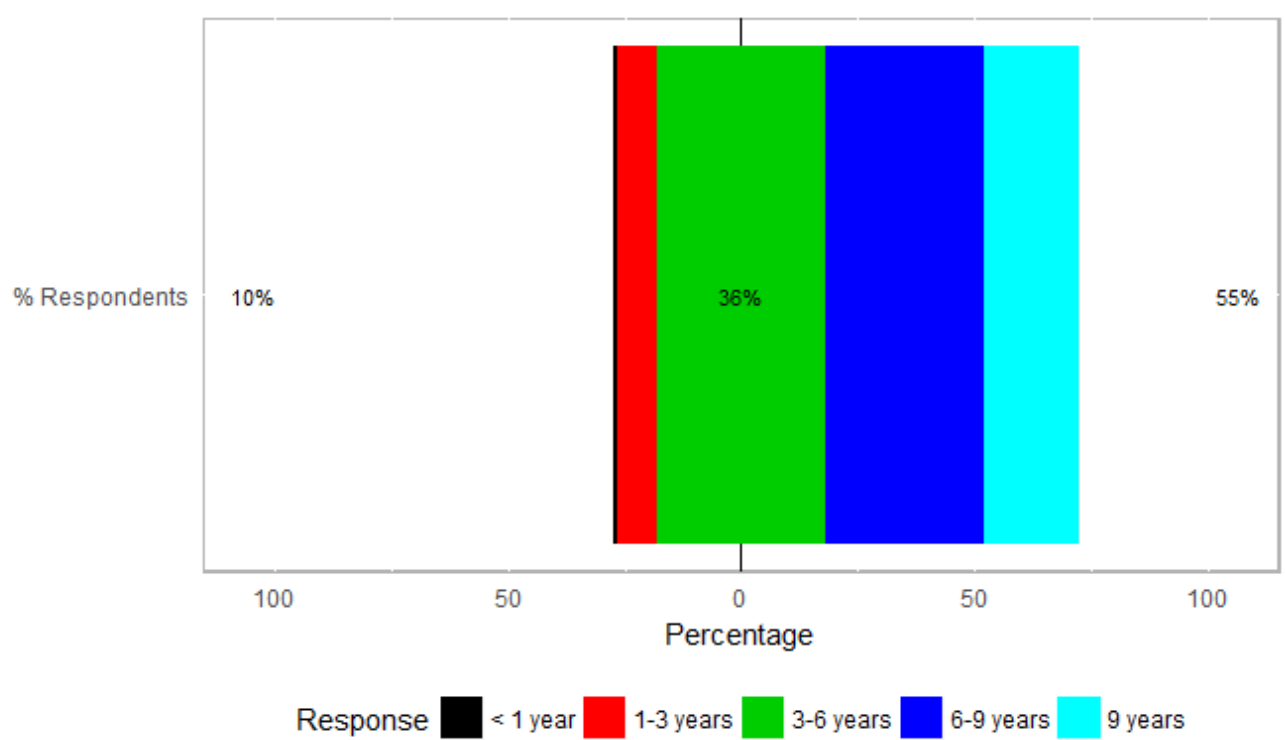

Figure 1.Time of use of social media.

Figure1 shows that a major proportion of respondents have got into social media less than a decade ago. A majority of respondents (36 percent) have been using social media for three to sixyears and equally many respondents (34 percent) said that they have been using social media for six to nine years. As many as 21 percent students responded that they have used social media for more than nine years. Only 1.1 percent respondents have used social media for less than a year. As depicted by the chi-square test $(\chi 2<2.2 \mathrm{e}-16)$, there exists significant difference among respondents who have been using social media across different times.

Likewise, the study also showed that majority of students (34 percent) use social media for 1 to 2 hours per day. Figure 2 shows that only 0.6 percent of the students do not use social media every day. A significant number of students (22.6percent) responded that they use social media for more than 3 hours per day.Figure 2 reveals that majority of students in Nepal use social media every day and it is an integral part of their lives. The chi-square test showed that there is significant difference in the per day use of social media by different students. The chi squared value was 6 . $513 \mathrm{e}^{-13}$ 


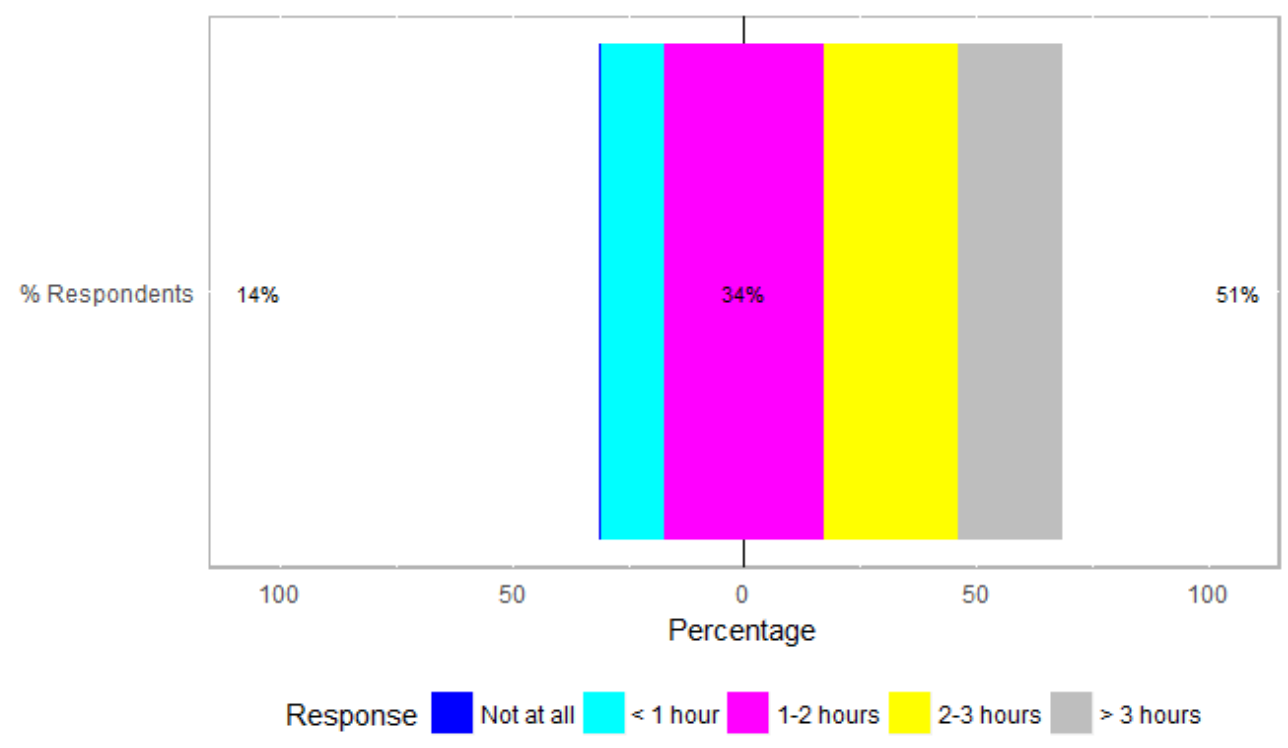

Figure 2.Per-day use of social media.

\section{Preference of connection and impact on habit}

The study revealed that a majority of the students, i.e. $58.4 \%$ preferred to primarily connect with friends via social media platforms that they were using. A $19.5 \%$ of respondents shared that they were using these platforms to connect with family members and relatives. Among them, 7.4\% reported to choose to be by themselves while being active in social media while the remainder of the respondents were using these platforms to connect with colleagues or build new connections with unknowns.

A 69 percent of respondents acknowledged that use of social media had led to some changes in their habits. Among these changes, most significant were seen in two aspects - sleep cycle and study. Out of $62 \%$ respondents who acknowledged this change in habit shared that they were sleeping later after beginning to use social media. Similarly, $26 \%$ of those who acknowledged change in habit reported that they felt most significant change in their study habit. 


\section{Impact on study hours}

Figure 3 revealed that social media engagement has led to a significant reduction in study time for the respondents. While $2 \%$ of respondents were studying for $9-12$ hours a day before they started actively using social media platforms, now only $0.6 \%$ of respondents gives equally many hours to studies. Similarly, while $42.5 \%$ of respondents were giving three to nine hours a day for studies, not only $27.64 \%$ of respondents do so. On the other end of the spectrum, while only $55.4 \%$ of respondents were spending less than three hours per day on studies, now the same has gone up to $71.76 \%$. It should be noted here that the respondents' distribution was significantly different over different hours of class rangesfor both before $\left(\chi 2=<2.2 \mathrm{e}^{-16}\right)$ and after $\left(\chi 2=2.2 \mathrm{e}^{-16}\right)$ they started becoming active in social media.

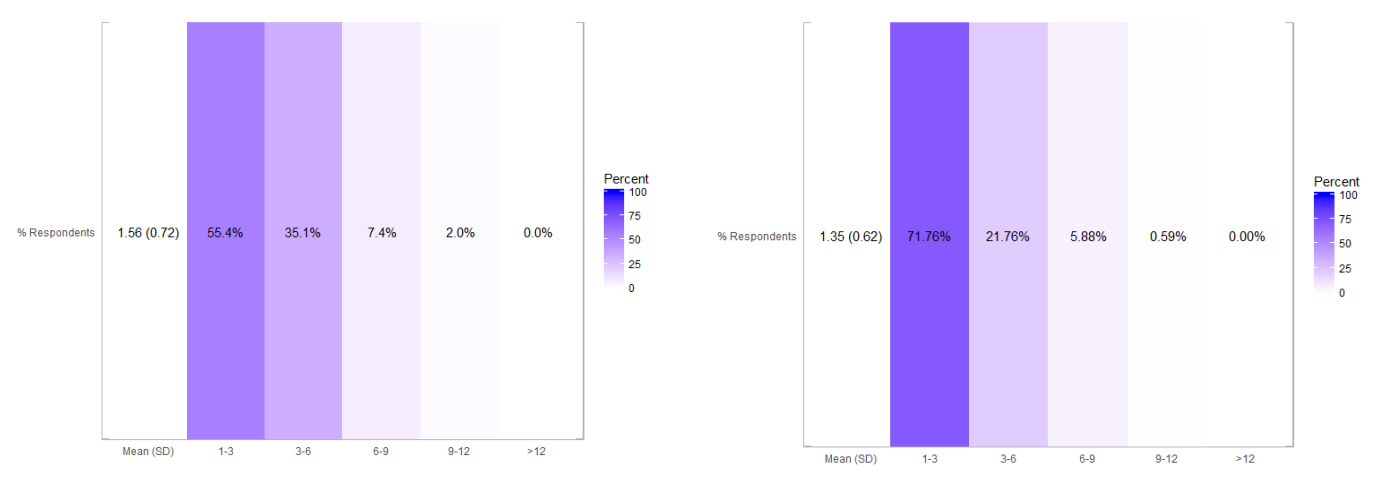

Figure 3. Impact of social media usage on study hours (before being active in social media, and after).

\section{Impact of Social Media onStudy}

As reflected by the heat plot in figure 4 , for most of the respondents $(36.4 \%)$, the use of social media moderately impacted their studies. However, a total of $59.5 \%$ respondents reported that their study was either least affected or feebly affected or not affected at all by the use of social media. The mean of the response on the scale of 1 to 5 reflectsa value of 3.14 , with a standard deviation of 1.3. The responses were also significantly different among each other $\left(\chi 2=9.887 \mathrm{e}^{-14}\right)$. 


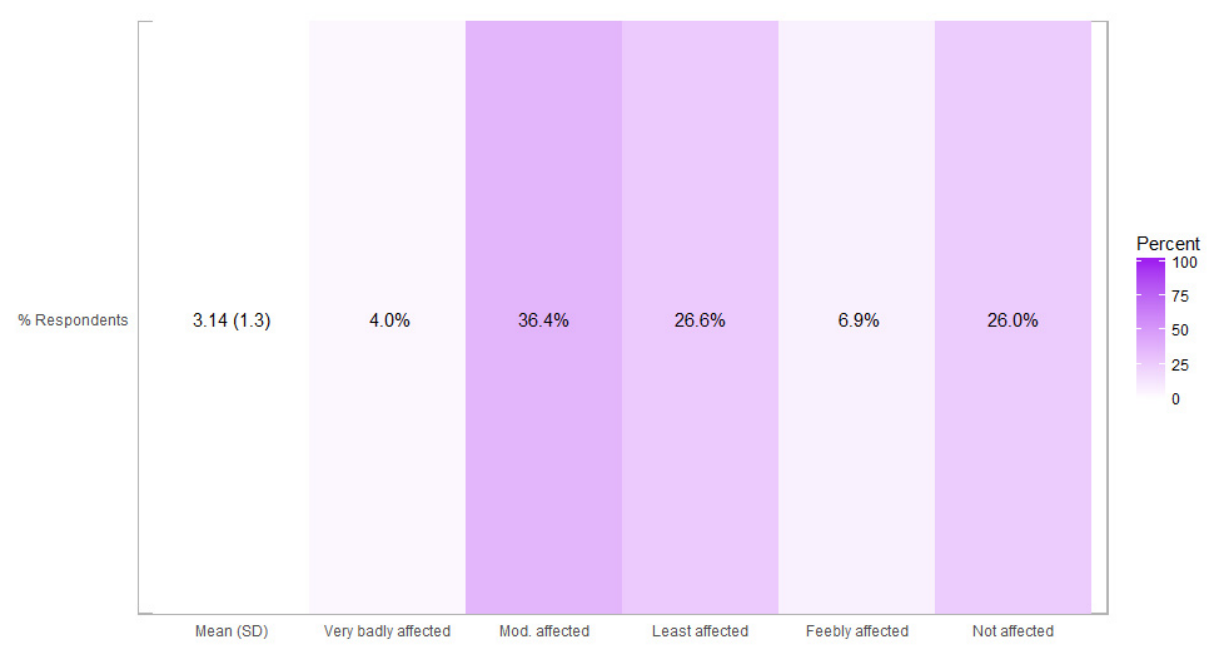

Figure 4. Heat plot showing effect of use of social media on study.

\section{Effect of social media on academic performance}

Figure 5represents the density plot showing the distribution of the percent decrease in academic percentages due to the use of social media and the vertical line reflects the mean value.36\% of total respondents reported that use of social media had caused their academic performance to decline by $0-5 \%$. However, almost equally many, i.e. $33.7 \%$ reported that use of social media had caused a decline of $5-10 \%$ on their academic performance, and another $15 \%$ reported a dip in performance of greater than 15\%. Overall, the study revealed that among the sampled students, engagement in social media was having a negative impact on their academic performance.

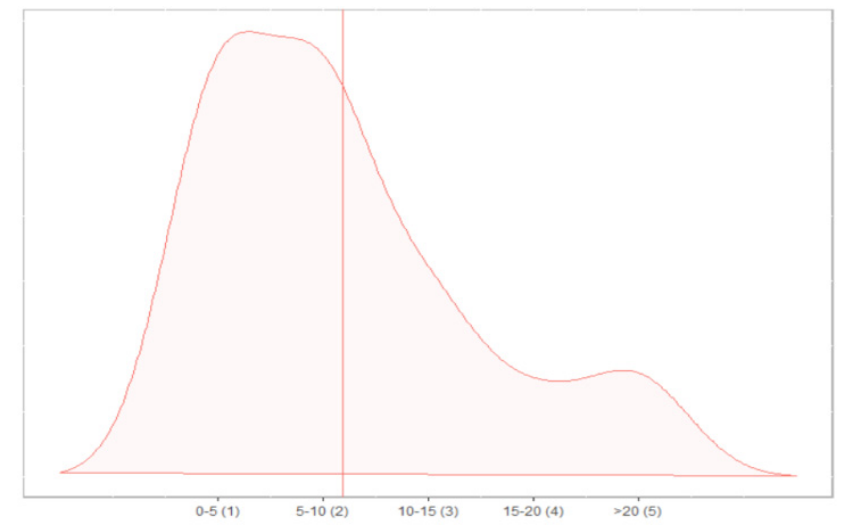

Figure 5. Density plot showing effect of social media on student performance (percent). 


\section{Impact of social media on test scores of students}

Figure 6 shows the comparison between the test scores of the respondents by the grade that they were enrolled in revealed that Bachelor $1^{\text {st }}$ year students were securing lowest scores in their exams. High school students were found to be securing higher marks at an average of $63 \%$ per student. During undergraduate level, the mean score of students was found to be lesser than high school level, and even within the undergraduate level, first year students were found to be scoring lowest in their tests. This could partly be explained by the general trend in Nepal where students from all over the country travel to major cities to pursue their higher studies, and in this phase, they make the highest number of new friends. The impact of social media usage in study hours as well as students' preference of social media platforms and who to connect with in these platforms corroborates this finding on impact of social media usage on test scores in light of thisgeneral Nepalese context.

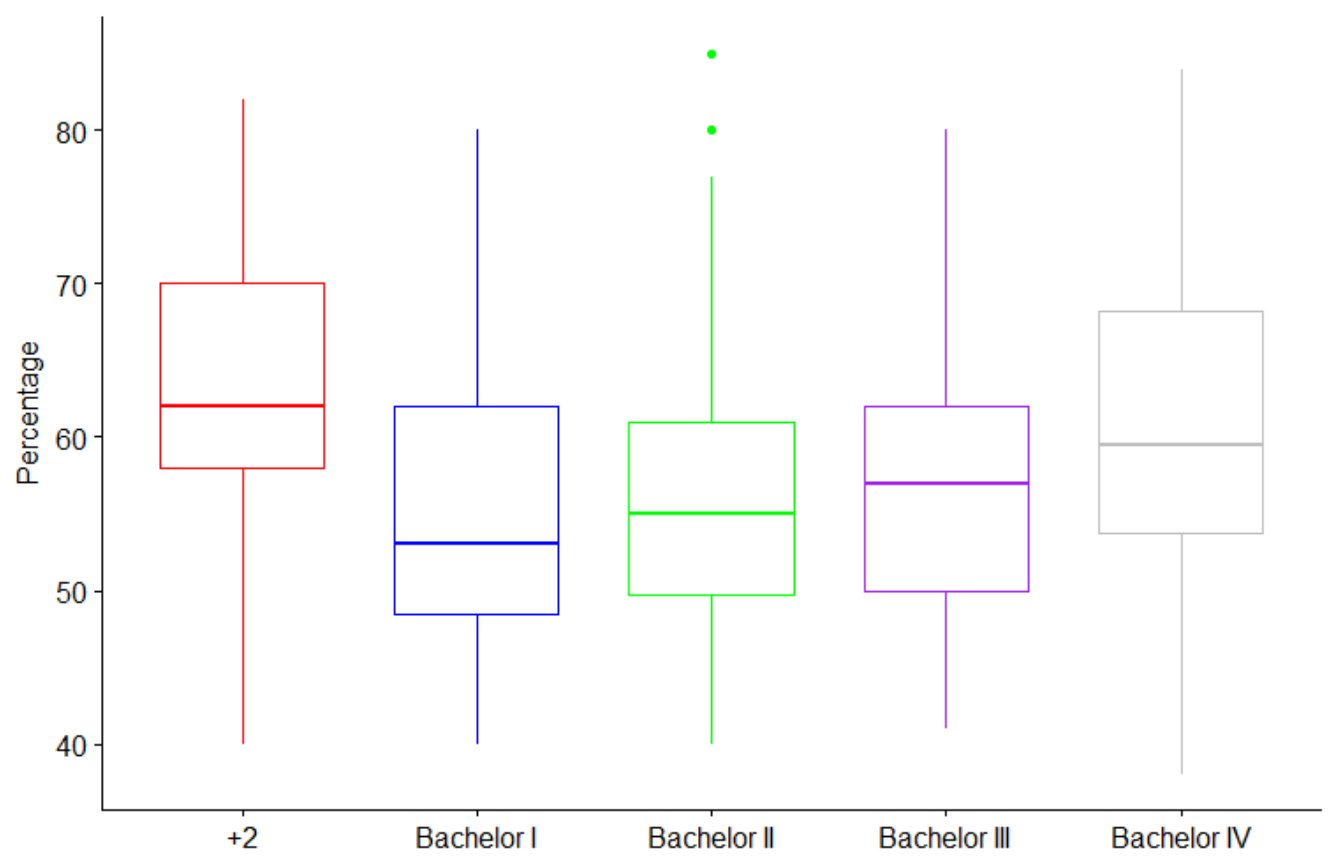

Figure 6. Impact of social media usage on test scores (by grade).

\section{Overall impact of social media on academic performance of college students}

The survey also asked students to share their reflections on the impact of use of social media on their own academic performance. Students were asked to rank their reflection on a scale of one to five where one signified that students strongly agreed with the proposition and five signified that they strongly disagreed with it. Twelve propositions were offered to the students, including but not limited to, social media engagement leads to drop in academic performance; social media causes distraction leading to negative impact on academic performance; games and social 
networks weaken the concentration of students; social media helps enhance connections with teachers and classmates; stopping use of social media would improve academic performance; social media improves reading skills; and social media causes deterioration of grammar and spelling. Mean values of scores assign by the students themselves on these propositions range from 1.38 to 4.51 . Overall, the result indicates that most of the college students tend to strongly agree that proper use of social media enhances academic performance. However, it can also be observed that addiction to social media is becoming a problem for it currently affectingstudents' academic life negatively. Most of the college students find it hard to concentrate on studies because social media offers a quick and pleasant distraction in the form of various games, chat windows, opportunities to post photos and status updates, etc. To some, social media provides a very useful platform to connect with peers and teachers and discuss course and test materials. Most of respondents are unsure about whether the use of social media has improved their reading skills or use of English language, or actually caused a deterioration of the same. That said, a majority of the students strongly disagree with the statement that social media network sites are personal/social and thus cannot be used for educational purposes.

\section{Students' perspective on future use of social media}

Even though the responses reflect that the students' academic performance has been negatively impacted by the use of social media, 89 percent of the respondents believe that the use of social media should not be stopped altogether as shown in figure 7 . This is an important finding and begs for a discourse on how social media can be leveraged to create a positive impact on students' academic performance if the students are not readily willing to give up the use of these platforms. These results support the need to reorient existing teaching learning practices and build new IToriented teaching pedagogy.

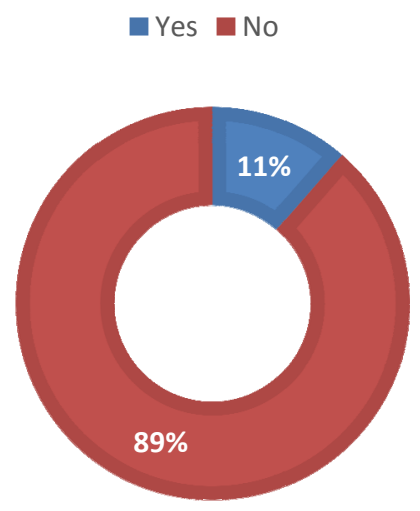

Figure 7. Willingness to give up use of social media. 


\section{Discussion}

The study has revealed that there exists a negative relation between the use of social media and the academic performance of students, with more than 80 percent students reporting a decline in their academic performance due to the use of social media. Similar findings were also identified by Al-Menayes (2015) and Acheaw and Larson (2015). The negative impact can be attributed to the use of social media platforms to build digital connections with acquaintances and share updates about personal or general events rather than using available groups and forums to engage in discussions with like-minded individuals or conducting other academia related activities (Yunus\& Salehi, 2012).

Similar pattern was evinced in thestudy, as itshowed that almost three quarters of the students joined social media within the past ten years of conducting the study with the highest proportion (36\%) using it for three to six years. The two highest go-to platforms for students were Facebook and Instagram. The amount of time spent by students on these platforms, when looked at in conjunction with the impact of social media usage on their academic performance points towards the fact that students have not been availing from the opportunities that social media offers to enhance educational outcomes to its potential. The survey has revealed that students prefer to limit their connection to friends and family, spend a significant amount of time on Facebook and Instagram, and are compromising their sleep hours and study hours to make time for social media usage. Currently, social media is acting more like a distraction in the form of opportunities to share status, stories, post photos, play games, and chat. Very small number of students are using social media as a means to connect with their educators. Half of the respondents acknowledged that their academic performance has declined more than 5\% since using social media. Sivakumar (2020) in his study also demonstrated similar threats that could negatively impact the academic performance of the students. Likewise, Peter (2015) also mentioned that students are addicted to social media and thus creating the right balance between academic and non-academic use to mitigate potential threat of academic performance degradation is imperative.

Having said that, strictly regulating the usage does not appear be the best move to improve students' learning. Even the go-to social media platforms like Facebook can be used as an effective tool to complement classroom learning, and if done right, social media can be used as added hours of learning (Moghavvemi\&Salarzadeh, 2018). As students seem reluctant to give up the usage in the future despite acknowledging that their indulgence on social media is causing a negative impact in their studies, there is a need to incorporate use of social media into the pedagogy to enable educators and students to harness the potential of social media in enhancing the academic performance. Different scholars, like Mensah and Nizam (2016), Sivakumar (2020), and Onyeka, Sajoh and Bulus (2013), in their research also suggested that in light of abnormal use of social media, education institutes should engage in spreading awareness regarding proper and positive use of such platforms such that the academic performance of the students can be enhanced. Likewise, their findings also revealed that proper usage of social media where students engage in learning platforms than other distractive materials on the internet, the academic performance is bound to improve. Thus, both teachers as well as students should be educated and encouraged to use interactive forum for teaching and learning activities (Olowo et al., 2020).

The potential improvement in academic performance by aforementioned suggestions is supported by the fact that over $90 \%$ of students believe that the use of social media should not be stopped. 
Even though most of the students have not been able to benefit academically from social media, they tend to believe that social media can contribute positively to learning.

\section{Conclusion}

From the survey of 176 students, it is seen that social media is having a negative impact on the academic performance of students. Yet most students feel that its use should not be stopped. Literatures support the possibility of leveraging social media as a complementary to classroom learning. Hence, it now falls on the educators to work with the students to explore avenues for incorporating use of social media into the pedagogy. The study suggests the student community to be aware of the pros and cons of using social media as well as theyshould be engaged in teachinglearning activities through the use of recent information technologies so that group as and project work can be formulated in the curricula by the educators to enhance collaborative learning. The study on undergraduate level students covering large scope of study would further recommend the suggestions and ideas for innovative ideas to build-in use of social media in the pedagogy.

\section{References}

Acheaw, O., \& Larson, A. G. (2015). Use of social media and its impact on academic performance of tertiary institution students: A study of students of Koforidua Polytechnic, Ghana. Journal of Education and Practice, 6(6), 94-101.

Ahmed, I. \& Qazi T. F. (2011). A look out for academic impacts of social networking sites: A student-based perspective. African Journal of Business Management,5(12), 5022-5031.

Al-Menayes, J. J. (2015). Social media use, engagement and addiction as predictors of academic performance. International Journal of Psychological Studies, 7(4), 86-94.

Asad, S., Abdullah-Al-Mamum M. D. \& Clement, C. (2012). The effect of social networking sites to the lifestyles of teachers and students in higher educational institutions. International Journal of Basic and Applied Sciences, 1(4), 498-510.

Asur, S., \& Huberman, B. (2010, March). Predicting the future with social media [Paper presentation]. Proceedings 2010 - IEE/WIC/ACM International Conference on Web Intelligence.

Baruah, T. D. (2012). Effectiveness of social media as a tool of communication and its potential for technology enabled connections: A micro-level study. International Journal of Scientific and Research Publications, 2(5), 1-10.

Boateng, R. \&Amankwaa, A. (2016). The impact of social media on students' academic life in higher education. Glob J Hum Soc Sci: G Linguistics and Education, 16(4), 1-9.

Boyd, D. M., \& Ellison, N. B. (2007). Social network sites: Definition, history, and scholarship. Journal of Computer-Mediated Communication, 13(1), 210- 230.

Brown, S. (2010). From VLEs to learning webs: The implications of Web 2.0 for learning and teaching. Interactive Learning Environments, 18(1), 1-10.

Cooper, D. R.,\&Schindler,P.M (2003). Business Research Methods.New Delhi: TataMcGrawHill. 
Coyle, C., \& Vaughn, H. (2008). Social networking: Communication revolution or evolution? Bell Labs Technical Journal, 13(2), 13-17.

Devi, K. S., Gouthami, E., \& Lakshmi, V. V. (2019). Role of social media in teaching-Learning process. Journal of emerging technologies and innovative research, 6(1), 96-103.

Kolan, B. J., \&Dzandza, P. E. (2018). Effect of social media on academic performance of students in Ghanaian Universities: A case study of University of Ghana, Legon. Library philosophy and practice (e-journal). https://digitalcommons.unl.edu/libphilprac/1637

Liccardi, I., Ounnas, A., Pau, R., Massey, E., Kinnunen, P., Lewthwaite, S., ... \& Sarkar, C. (2007). The role of social networks in students' learning experiences. ACM Sigcse Bulletin, 39(4), 224-237.

Mahmud, R., \& Bukhari, M. (2019). Usage intensity of social media and academic performance. International Journal of Recent Technology and Engineering, 8(4), 6675 6678 .

Mehmood, S. \&Taswir, T. (2013). The effects of social networking sites on the academic performance of students in college of applied sciences. InternationalJournal of Arts and Commerce, 2(1), 111-125.

Mensah, S. O., \& Nizam, I. (2016). The impact of social media on students' academic performance - A case of Malaysia Tertiary Institution. International Journal of Education, Learning and Training, 1(1), 14 - 21.

Moghavvemi, S. \&SalarzadehJanatabadi, H. (2018). Incremental impact of time on students' use of E-learning via Facebook. Br J EducTechnol, 49: 560-573.

Negussie, N. \&Ketema, G. (2014). Relationship between Facebook practice and academic performance of Universitystudents. Asian Journal of Humanities and Social Sciences, 2(2), $1-7$.

Olowo, B. F., Alabi, F. O., Okotoni, C. A., \& Yusuf, M. A. (2020). Social media: Online modern tool to enhance secondary school students' academicperformance. International Journal on Studies in Education, 2(1), 26-35.

Onyeka, N. C., Sajoh, D. I. \&Bulus, L. D. (2013). The effect of social networking sites usage on the studies of Nigerian students. The International Journal of Engineering and Science, (2) 7, 39-46.

Palla, I.A. \& Sheikh, A. (2020). Impact of social media on the academic performance of college students in Kashmir. Information Discovery and Delivery, https://doi.org/10.1108/IDD-062020-0061

Peter, O. (2015). Social media and academic performance of students in University of Lagos. Department of Educational Administration, Faculty of Education, University of Lagos.

Sivakumar R. (2020). Effects of social media on academic performance of the students.Samwaad - e-journal, 9(2):90-97.

Yunus, M. M., Nordin, N., Salehi, H., Embi, M. A., \& Salehi, Z. (2013). The use of information and communication technology (ICT) in teaching ESL writing skills. English language teaching, 6(7), 1-8. 